\title{
Synthesis and Characterization of Mineral Wollastonite Particulate Filled Vinyl-Ester Resin Composites
}

\author{
B. Amarababu ${ }^{1, *}$, V. Pandu Rangadu ${ }^{2}$ \\ ${ }^{1}$ Department of Mechanical Engineering, PBR Visvodaya Institute of Technology \& Sciences, \\ Kavali - 524201, Nellore District, Andhra Pradesh, India \\ ${ }^{2}$ Department of Mechanical Engineering, Jawaharlal Nehru Technological University Anantapur, \\ College of Engineering (Autonomous), Anantapur - 515002, Andhra Pradesh, India \\ *E-mail address: amarphd2011@gmail.com
}

\begin{abstract}
In the present research presents influence of coupling agent $1 \%$ triethoxymethyl silane sprayed on to the wollastonite particulate powder before it dispersed into the vinylester/composites. Firstly two different composites were developed in which wollastonite is filled with vinylester resin and same wollastonite was sprayed with coupling agent $1 \%$ triethoxymethyl silane then filled with vinylester resin. The particle functionalization with a bi-functional coupling agent $1 \%$ triethoxymethyl silane was observed to have a significant effect on the curing process and subsequent physical properties of the composites. Wollastonite functionalization favors the composite fabrication with a lower curing temperature as compared to the as-received particle filled vinyl ester resin composites. Thermogravimetric analysis showed an increased thermo-stability in the particles functionalized filled vinyl ester resin composites as compared to the unmodified particle filled counterparts. The uniform particle dispersion and the chemical bonding between filler and vinyl ester resin matrix were found to contribute to the increased thermal stability and enhanced tensile strength and modulus.
\end{abstract}

Keywords: vinylester; wollastonite; SEM; TGA; mechanical properties

\section{INTRODUCTION}

The existing challenges in the composite fabrication are to obtain uniform filler dispersion and to introduce strong chemical bonding between the micro size particles and the polymer matrix, which are necessary to provide a high tensile strength due to local stress within the composite. The interfacial interactions between fillers and polymer matrix play a crucial role in determining the quality and properties of the composites. The poor bonding linkage between the fillers and polymer matrix such as composites made by simple mixing will introduce artificial defects, which consequently result in deleterious effect on the mechanical properties of the composites. Introducing good linkages between the fillers and the polymer matrix is still a challenge for specific composite fabrication. However, appropriate chemical engineering treatment of the microfiller surface by introducing proper functional groups could improve both the strength and toughness of the subsequent 
composites with improved compatibility between the fillers and the polymer matrix, and make the composites stable in harsh environments too. Thus, surface functionalization of particles with a surfactant or a coupling agent is important not only to stabilize the particles during processing but also to render them compatible with the polymer matrix [1-15].

It is a common practice that reinforcing agent in to the matrix makes good strength, lower price and relatively good adhesion to matrix, but nowadays minerals are in more demand because of a few drawbacks of glass fibers such as lower dispersion, lower thermal and chemical stability and liberation of large amount of heat while processing. Wollastonite is a naturally occurring calcium metasilicate available in surface coated froms of various types. Purity after processing is about $97 \%$ of the particles are needle shaped, microfibrrous, of about $50 \mu \mathrm{m}$ in size. New grades under development indicates its string growth and its potential for replacement of calcinated clay and other minerals used in thermoplastic [16-29]. Wollastonite is a naturally occurring calcium silicate mineral. Earlier studies have shown that acicular wollastonite can be used as co-reinforcing agent in short fiber composites. Use of wollastonite in high fraction will reduce the cost of composite and improve tensile strength, impact properties and dimensional stability. High aspect ratio of wollastonite is retained by appropriate milling thus its greater surface area better intercepts stress propagation. Reinforcement with wollastonite increases the starting crystallization temperature and induces a shorter processing time in injection molding and thus the effect of crystallinity of the composite for this reason reinforcement of rotational molded articles with wollastonite is an interesting possibility. These materials are interesting as they show an increase in flexural modulus, superior dimensional stability, reduces the cost and ease processability.

Vinyl-ester resin, as a structural polymer, was chosen as a polymer matrix in current study due to the fact that the cured resins are thermosetting with a network structure possessing high resistance to the moisture and chemicals, and good mechanical properties. Thus the resultant composites have the potential applications in fabrication and building materials such as electrodeposition tanks, automotive parts and marine vessels which require superior mechanical properties and/or high resistance to harsh environments such as strong acid or base. Furthermore, the functional groups of the polymer surrounding the nanoparticles enable these nanocomposites as good candidates for various applications such as site-specific molecule targeting in biomedical areas [30-39].

This paper presents the effect of particle functionalization by a bi-functional $1 \%$ triethoxymethyl silane on the vinyl ester resin curing process and the optimum conditions for high-quality composite fabrication were investigated. The functionalized wollastonite particles reinforced vinyl ester composites showed enhanced mechanical properties. The composites containing the functionalized wollastonite particles showed improved thermal stability as compared with the composites reinforced with the as-wollastonite particles.

\section{MATERIALS AND METHODS}

In the present work, a commercially available vinylester, methyl ethyl ketone peroxide (catalyst), Cobalt napthenate (accelerator) were purchased from the V.G.R. Enterprises, Madhurai, Tamialnadu, India. Vinyl-ester monomers with two reactive vinyl end groups enable the cross-linking for network formation. The liquid resin has a density of $1.045 \mathrm{~g} / \mathrm{cm}^{3}$ and a viscosity of 350 centipoises (cps) at room temperature. The grade of wollastonite (W) used for preparing different compositions was Fillex-11AB3 (surface treated), supplied by Wolkem India Limited. Aspect ratio 15:1 or > 100; density $2.9 \mathrm{~g} / \mathrm{cm}^{3}$; Moh's hardness 4.5-5; 
PH: 9-10; melting point: $1450^{\circ} \mathrm{C}$. The total fiber volume fraction was fixed at $40 \% .1 \%$ triethoxymethyl silane was purchased from Sigma-Aldrich Chemical Company. All the chemicals were used as-received without further treatment.

\section{1. Composite preparation}

The vinylester (VE)/ wollastonite (which is particulate form) composites were made first adding the methyl ketone peroxide $(1.2 \mathrm{~mL})$ in to the VE resin $(100 \mathrm{~g})$. The wollastonite $(0,5,10,15,20,25$, and 30) was mixed separately with the above resin, catalyst and wollastonite particles. After mixing is over, 15 min resting time was allowed for wetting the wollastonite powder and to reduce heterogeneity in the samples. Cobalt napthenate $(0.7 \mathrm{~mL})$, accelerator was added with resin and wollastonite mixture. Before curing the mixtures were degassed and poured into the mould having cavity volume of $300 \times 300 \times 3 \mathrm{~mm}^{3}$. The VE composite system was cured at atmospheric for $24 \mathrm{hr}$ and then post cured at $70{ }^{\circ} \mathrm{C}$ for $2 \mathrm{~h}$ to ensure completes curing. Next, coupling agent $1 \%$ triethoxymethylsilane in acetone was sprayed on to the wollastonite powder and then gave some time i.e. $15 \mathrm{~min}$ to dry. Then same sprayed wollastonite was used to prepare another composite. The above procedure was repeated for fabricating another composite.

\section{2. Mechanical Testing}

Tests for determining tensile strength and tensile modulus mechanical properties were conducted on computer controlled Instron 3399 type universal testing machine. For tensile test, standard dumbbell specimen shaped specimens were prepared on par with ASTM D638. The cross head speed was maintained $50 \mathrm{~mm} / \mathrm{min}$. The test speed was maintained between 1.3-1.5 mm/min. Izod Impact strength was determined using Izod charpy digital tester, as per ASTM D256. Shore D hardness test was conducted according to ASTM D 2240.

\section{3. Thermal \& Morphology testing}

The thermal characteristics TGA, DSC measured on polymer composites using SDT Q600 TGA/DSC (TA Instruments) at a rate of $10{ }^{\circ} \mathrm{C} / \mathrm{min}$ under nitrogen flow measurements were carried out at $20{ }^{\circ} \mathrm{C}$ temperature, $40 \%$ relative humidity. A JEOL JSM-6400 JAPAN scanning electron microscope at $15 \mathrm{kV}$ accelerating voltage was equipped with energy dispersive spectroscopy (EDS) to ascertain the filler interfaces with the matrix. Fractured specimen surfaces were gold-coated and the fractures surface was observed using a scanning electron microscope.

\section{4. Chemical resistance test}

Chemical resistance test was studied as per the ASTM D 543 method. For this purpose $15 \%$ concentrated $\mathrm{HCl}$ and $15 \% \mathrm{NaOH}$ were used. Pre-weighted samples were dispersed in these for five days and removed, washed thoroughly with distilled water and dried immediately by pressing them on both sides with tissue paper. From the final weights of the samples, \% wt. loss/gain was determined. The chemical test was repeated for five samples in each case and the average values were repeated.

\section{5. Water absorption test}

Rectangular specimens were cut from each sample with dimensions of 20 X20 m². The sample were dried in oven at $50{ }^{\circ} \mathrm{C}$ for $24 \mathrm{~h}$, and then cooled in desiccators and 
immediately weighed of the nearest $0.001 \mathrm{~g}$. In order to measure the water absorption of the composites, all the samples were immersed in water for about at room temperature as described in ASTM D 570-99 (ASTM 1999) procedure. Excess water on the surface of the samples removed before weighing. Three replicate samples were tested and the results were presented as an average of the tested specimens. The percentage increase in weight during the immersion was calculated as follows:

$$
\text { Percentage water absorption }=\frac{\text { Wet weight-Dry weight }}{\text { Dryweight }} X 100
$$

\section{RESULTS AND DISCUSSIONS}

\section{1. Hardness}

Fig. 1 shows the variation of hardness as a function of Wollastonite of (a) without coupling agent and (b) with coupling agent of vinylester composites. Hardness of the wollastonite particulates filled vinylester increases with increasing wollastonite particulates.

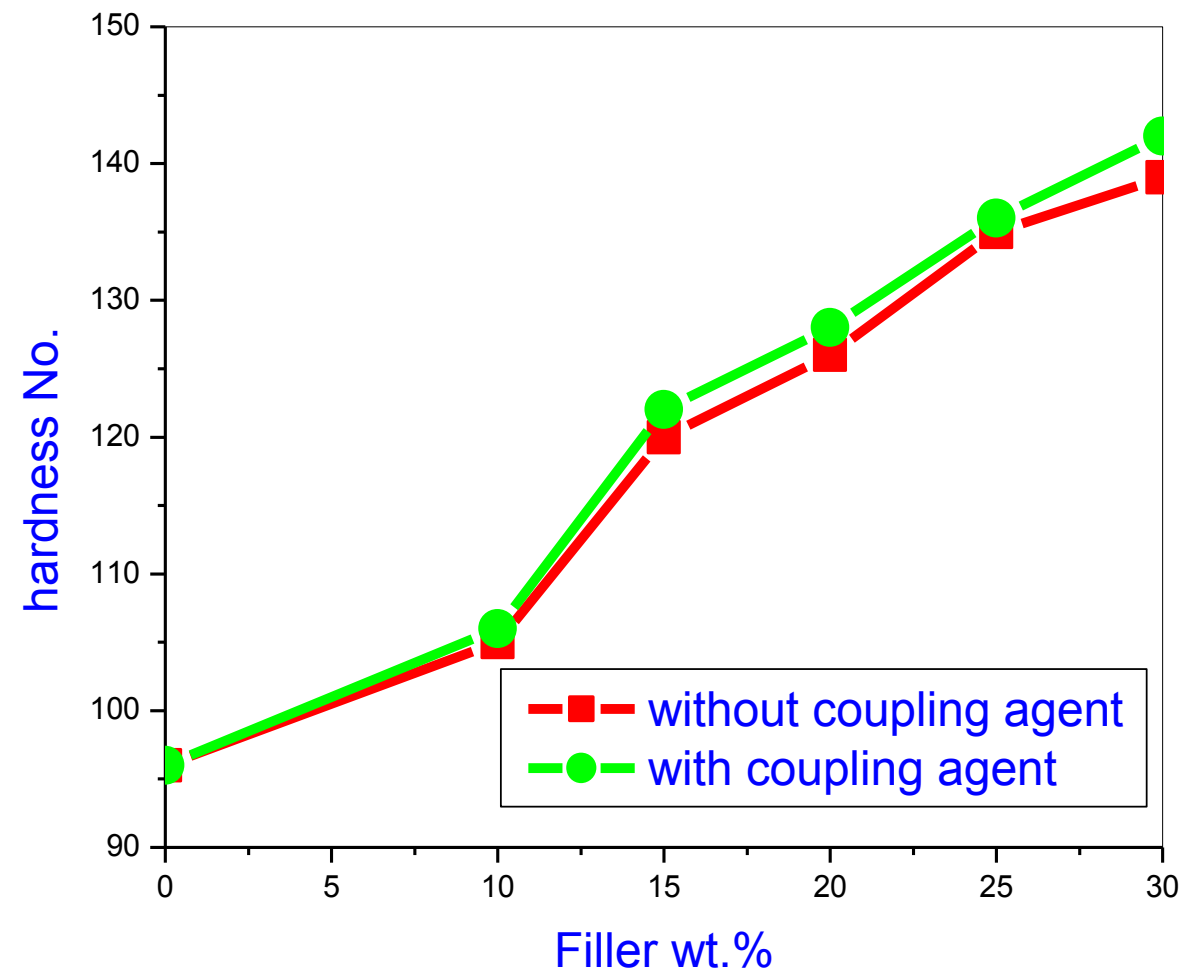

Figure 1. Variation of hardness as a function of Wollastonite at (a) Without coupling agent and (b) with coupling agent of vinylester composites.

This trend is expected because, when more filler particles incorporated into the polymer matrix, the elasticity or flexibility of the polymer chain is reduced, resulting more rigid blends. Even after, spraying of coupling agent to the particle help to improved strength, 
because coupling agent imparts more bonding strength, adhesion and consequently that results, substantial interface between matrix and filler in all cases. Similar phenomenon was observed by the other authors $[1,4,5]$.

\section{2. Tensile strength}

From the Fig. 2 it was clearly observed that tensile strength of the pure vinylester matrix is $1023 \mathrm{MPa}$. The tensile strength of composites increases up to $25 \mathrm{wt}$. \% wollastonite powder $(1685 \mathrm{MPa})$ loaded into vinylester matrix. The increase in strength was due to good filler matrix interactions, which was largely due to the needle shaped structure might have enhanced ability of the filler. Needle type fillers have higher aspect ratio and this increases the wet ability of the fillers by the matrix, thus creating fewer micro voids between the filler and matrix. The filler has higher surface area due to its small particle size, tends to agglomerate and these results in the reduction of surface interactions between the matrix and the filler. This may be the substantial reason for reduction of tensile strength after $25 \mathrm{wt} \%$, whereas when filler was coated with coupling agent, might have provided still better adhesion, bonding between the filler and matrix and also just spraying coupling agent brings the significant results which is even better performance, than absence of coupling agent. Similar observations were observed from the literature $[12,15,18]$.

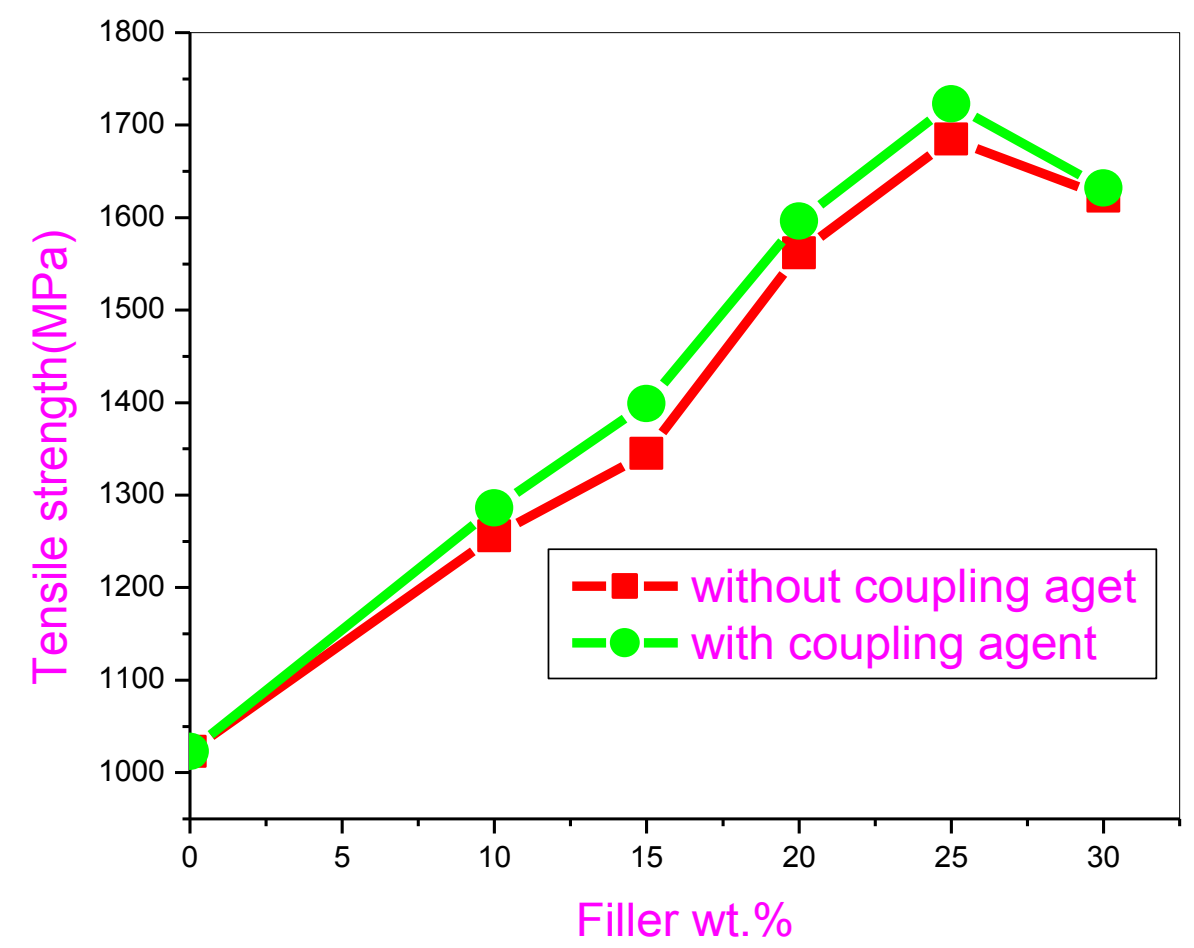

Figure 2. Variation of tensile strength as a function of Wollastonite at (a) Without coupling agent and (b) with coupling agent of vinylester composites.

Fig. 3 shows the variation of tensile modulus as a function of Wollastonite at (a) without coupling agent and (b) with coupling agent of vinylester composites. For pure VE tensile modulus was $42 \mathrm{GPa}$. Progressive increase of filler content in VE progressively 
increases the tensile modulus and at 30 wt. \% loading of filler composite shows a tensile modulus was $61 \mathrm{G} \mathrm{Pa}$.

The tensile moduli of all types of composites are found to be increased linearly with the increasing filler content in the matrix, indicating the positive toughening effect. The increased modulus is due to the presence of dispersed rigid particles.

The presence of wollastonite particles might have stiffened the matrix inducing the increased modulus. It was assumed that the space between the filler particles was filled with blend matrix minimizing the presence of voids and bubbles consequently leading to increase in modulus [18].

In case of coupling agent coated composites, magnitude of the modulus was increased even better than the composite which does not have the coupling agent, the attributed reasons are coupling agent facilitates good barrier for stress transfer. As filler could be the integral part of the matrix in other words coupling agent makes less gap between thereof.

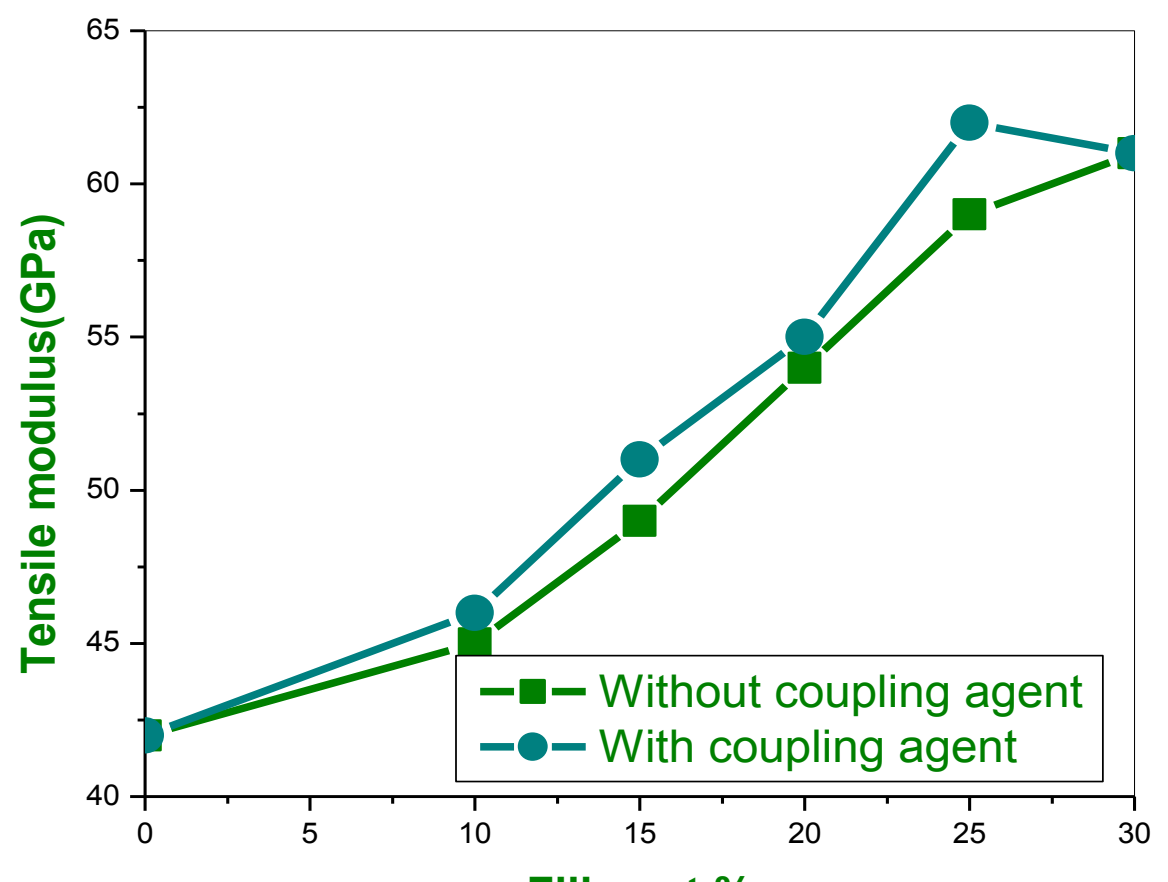

Filler wt. \%

Figure 3. Variation of tensile modulus as a function of Wollastonite at (a) Without coupling agent and (b) with coupling agent of vinylester composites.

\section{3. Impact strength}

Fig. 4 shows the variation of impact strength as a function of wollastonite for two different composites of (a) Without coupling agent and (b) with coupling agent composites.

For pure VE impact strength was $20 \mathrm{~J} / \mathrm{m}$ and with the addition filler in to the VE impact strength was improved linearly up to $25 \mathrm{wt}$. \% and the suddenly it was reduced at 30 wt. \%. Incorporation of rigid filler may enhance or deteriorate the impact properties of composites. Impact strength is an indication of tolerability for the sudden impact. When a 
composite is subjected to an impact, rapid crack propagation is initiated through the composite.

The improvement in the impact strength is due to the limited cross linked structure of the cured resin. The filler particle is tracer to move within the matrix and correspondingly, the matrix is free to stretch around particles. The stress transfer rate is becomes very low, which leads to the lowest impact strength. In the filled composites, as filler loading increases the tendency for agglomerates also increases then acts as stress concentration points or crack initiation sites. Therefore reduction of impact strength with increasing filler content is expected.

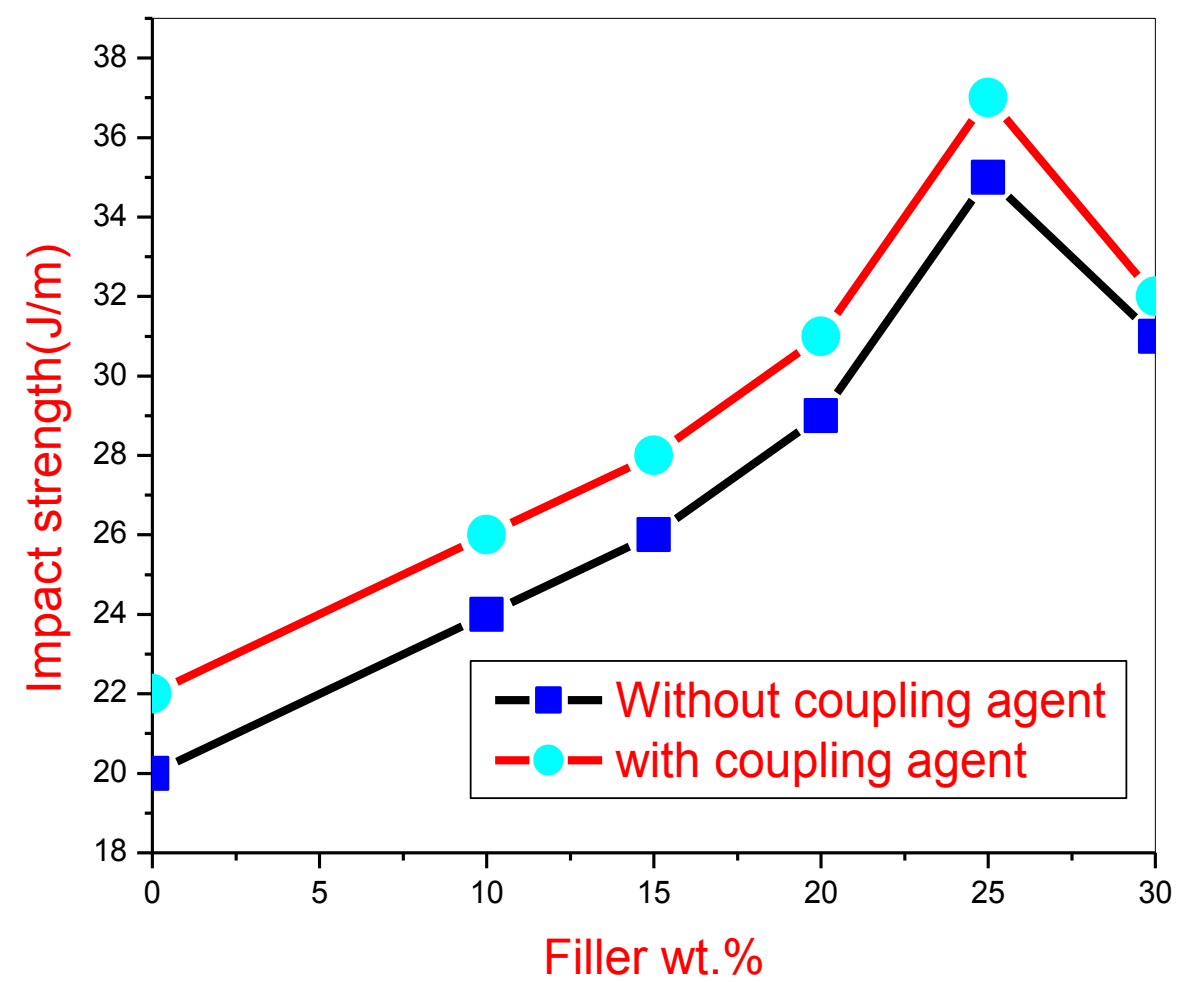

Figure 4. Variation of impact strength as a function of Wollastonite at (a) Without coupling agent and (b) with coupling agent of vinylester composites.

\section{4. Morphology studies}

Fig. 5 (a \&b) shows the morphological analyses of various samples of wollastonite filled in vinylester (a) without coupling agent and (b) with coupling coated composites. From the Fig. 5 (a) the fracture sample cross section were clearly indicates that filler distribution was homogeneous as there was only one voids, and two pullouts and also it is slightly looks like ductile nature of cross section was the genuine reason for improved performance at 25 wt. \%, on other hand in Fig. 5 (b) cross section was slightly somewhat different as it looks like more ductile nature as well as inter face was still better than the other microgram. 

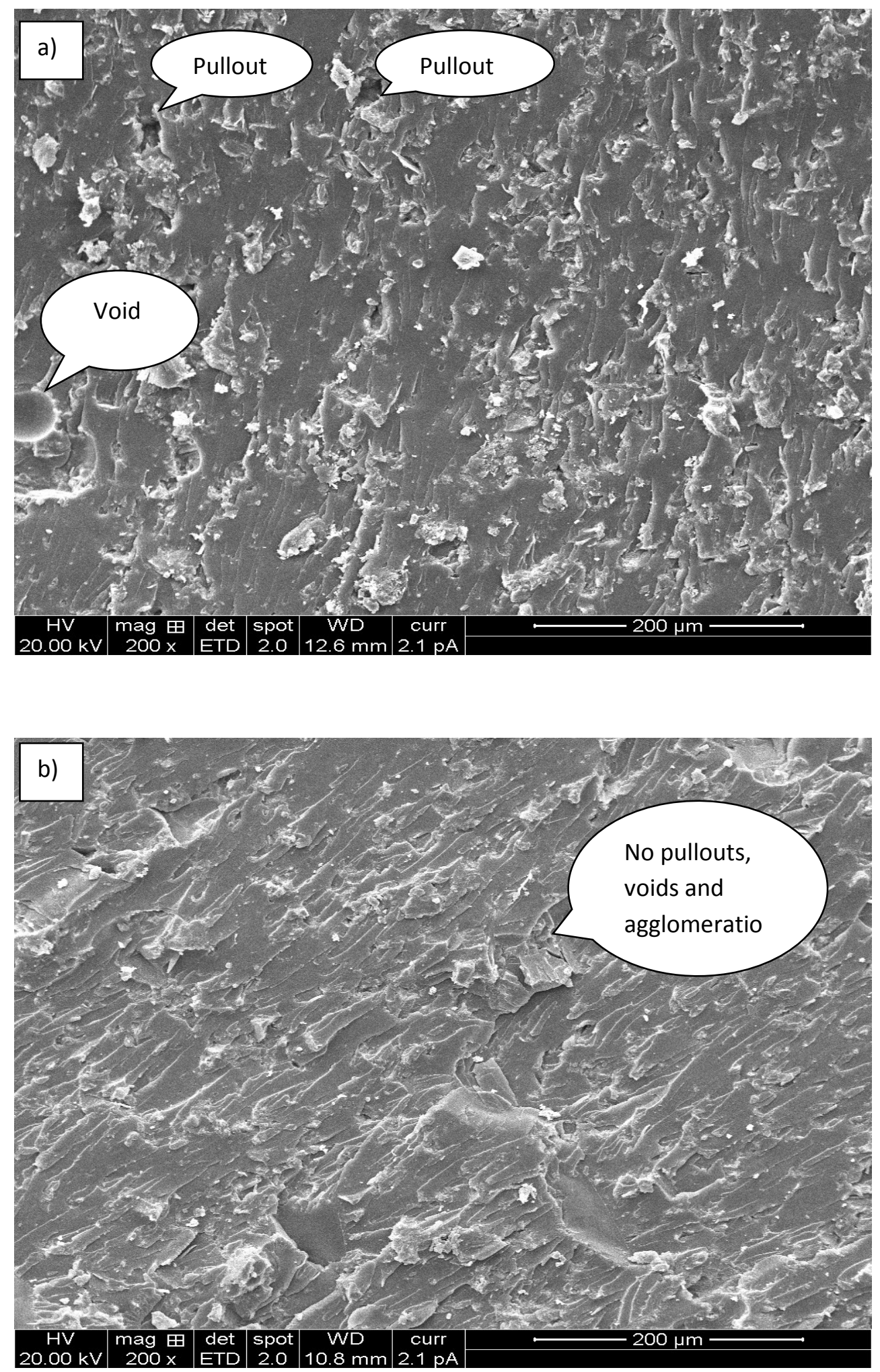

Figure 5. Morphological analyses of various samples of wollastonite filled in vinylester (a) 25 wt. \% without coupling agent and (b) 25 wt. \% with coupling coated composites. 


\section{5. Thermo gravimetric analysis}

Fig. 6 indicates the two different curves of 25 wt. \% filler loading with and without coupling agent sprayed. From these curves, maximum weight loss temperature, weight residue noted at $500{ }^{\circ} \mathrm{C}$ was observed. Reasons attributed that the increased thermal stability composites is due to spraying of coupling agent played instrumental in increasing the thermal stability of the composites. Composites absence of coupling agents was resisted up to $302{ }^{\circ} \mathrm{C}$, whereas on other hand thermal stability was significantly improved for the presence of coupling agent is moved up to $308{ }^{\circ} \mathrm{C}$, being particle coated with coupling agent can protect the particle without decomposing was the reason for improved thermal stability. Similar observations were fished out from the literature [25].

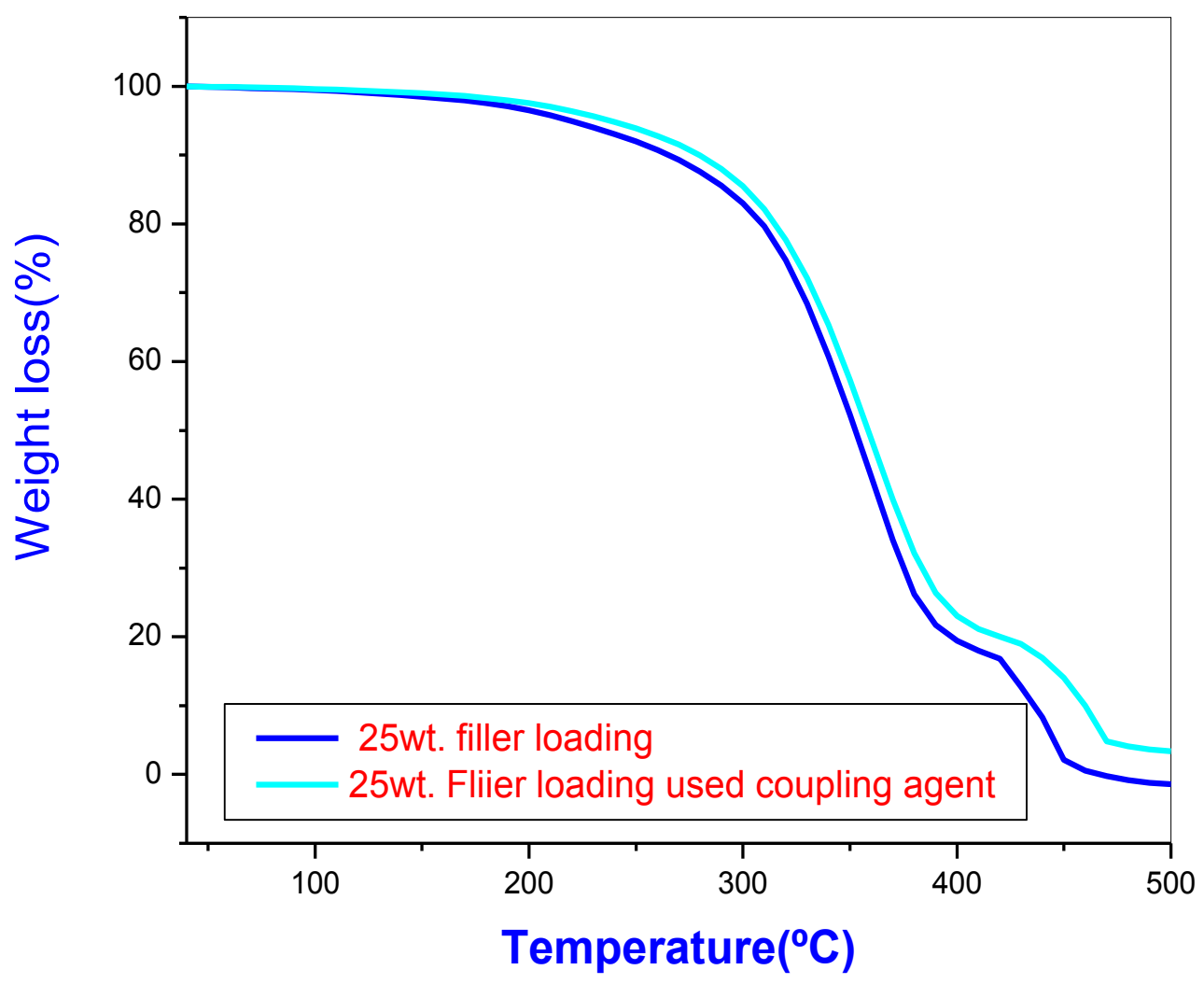

Figure 6. Variation weight losses as a function temperature of wollastonite filled vinylester of (a) 25 wt. \% without coupling agent and (b) 25 wt. \% with coupling coated composites.

\section{5. Chemical and water resistance}

The variation of chemical absorption of wollastonite filled VE composites in the presence and absence of CA were presented in the Table 1 and the variation of water absorption versus filler filled VE/ composites are shown in the Fig. 7. Indeed filler nature is hydrophilic. The composites made from this filler showed higher chemical and water uptake. It can be seen from the figure that the composites with higher filler content shows the more water and chemical absorption. This is due to the higher filler content increases the formation 
of agglomerations increases difficulties of achieving the uniform dispersion of filler. The agglomeration of the filler in composites increases the water and chemical absorption of the composite. In case of presence of coupling agent it will reduces hydrophilic nature as the particle will be coated or protected by saline layer that will key for reducing the water and chemical absorption.

Table 1. Acid and alkali absorption properties of cured vinylester (VE) resin and VE/ wollastonite composites of absence and presence of coupling agent (CA).

\begin{tabular}{|c|c|c|c|c|}
\hline \multirow[b]{2}{*}{ Composition } & \multicolumn{2}{|c|}{ Alkali absorption (\%) } & \multicolumn{2}{|c|}{ Acid absorption (\%) } \\
\hline & $\begin{array}{c}\text { Absence } \\
\text { of CA }\end{array}$ & $\begin{array}{c}\text { Presence } \\
\text { of CA }\end{array}$ & $\begin{array}{c}\text { Absence of } \\
\text { CA }\end{array}$ & $\begin{array}{c}\text { Presence of } \\
\text { CA }\end{array}$ \\
\hline $\mathrm{VE}+0$ wt. \%. filler & 0.423 & 0.424 & 0.105 & 0.107 \\
\hline $\mathrm{VE}+5$ wt. $\%$ filler & 0.432 & 0.441 & 0.168 & 0.178 \\
\hline $\mathrm{VE}+10$ wt. $\%$ filler & 0.441 & 0.445 & 0.201 & 0.217 \\
\hline $\mathrm{VE}+15$ wt. $\%$ filler & 0.476 & 0.476 & 0.214 & 0.219 \\
\hline $\mathrm{VE}+20$ wt. $\%$ filler & 0.479 & 0.478 & 0.219 & 0.220 \\
\hline $\mathrm{VE}+25$ wt. $\%$ filler & 0.485 & 0.486 & 0.236 & 0.240 \\
\hline $\mathrm{VE}+30$ wt. $\%$ filler & 0.489 & 0.490 & 0.234 & 0.232 \\
\hline
\end{tabular}

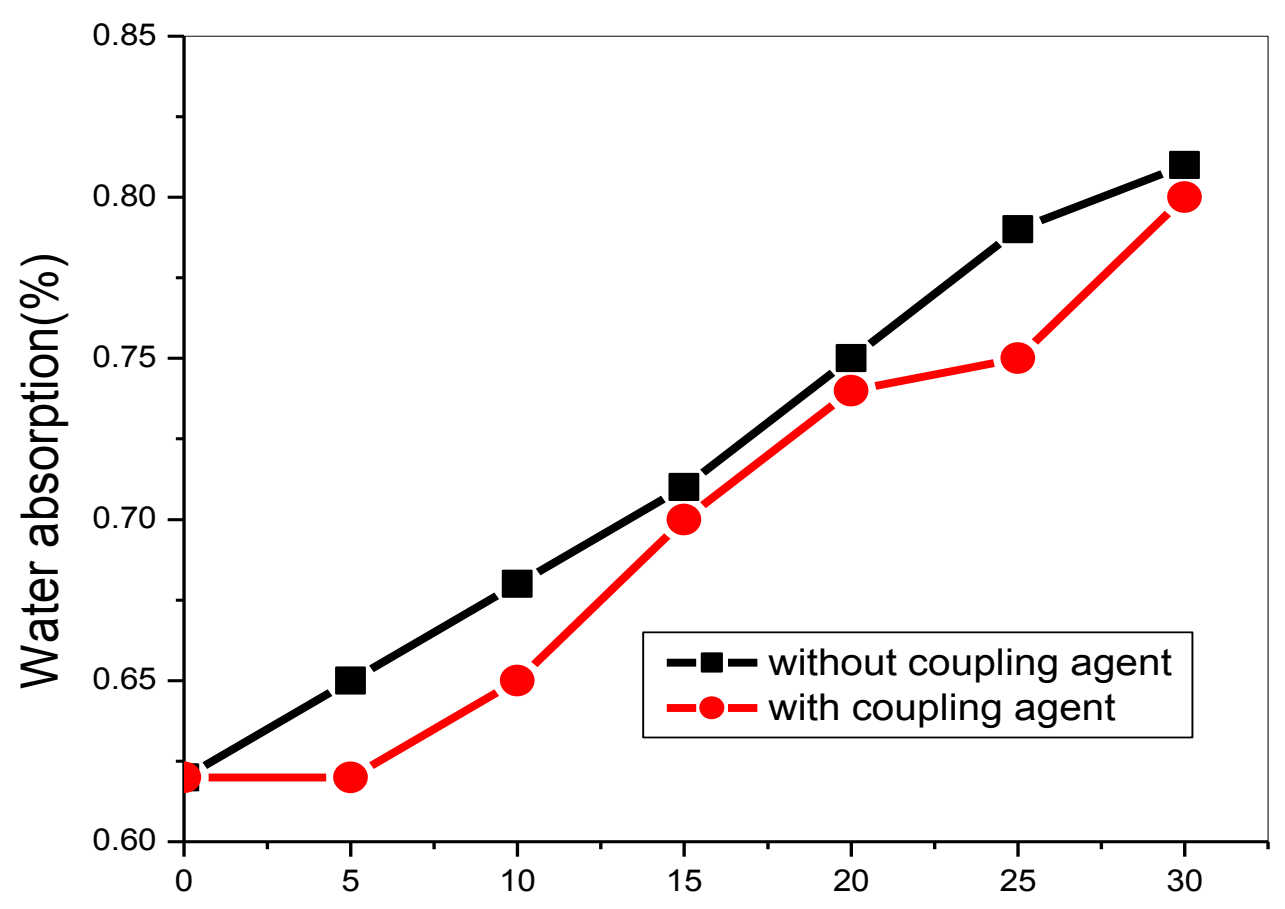

Filler wt.\%

Figure 7. Effect of wollastonite particle content on the water absorption of VE in the absence and presence of coupling agent. 


\section{CONCLUSION}

VE/ wollastonites composites have been prepared using casting method. The composite showed slightly higher tensile, and impact strength, when compared without coupling agent. Thermal stability was increased for coupling agent coated composites for about $6{ }^{\circ} \mathrm{C}$. The composites prepared had low chemical and water absorption for coupling agent coated filler composites. Composites prepared by the addition mineral filler have advantage of low overall cost.

\section{Acknowledgements}

Authors would like to thank the Department of Mechanical Engineering, GATES Institute of Technology, GOOTY, Andhra Pradesh, India and Department of Polymer Science \& Technology, SK University, Anantapur, Andhra Pradesh, India for their timely help in providing laboratories.

\section{References}

[1] Berthet J.F., Ferrier E., Hamelin P., Construction Building Materials 20(5) (2006) 338347.

[2] Rochdi E.H., Bigaud D., Ferrier E., Hamelin P., Compos. Struct. 72(1) (2006) 69-78.

[3] Colomb F., Tobbi H., Ferrier E., Hamelin P., Compos. Struct. 82(4) (2008) 475-487.

[4] Porter M.L., Mehus J., Young K., Barnes B., O’Neil E.F., Aging degradation of fibre composite reinforcement for concrete structures, In: Advanced comp mats in bridges and structures, 2nd Int. Conference, Canada; 1997. p. 641-648.

[5] Abanilla M.A., Li Y., Karbhari M., Compos Part B: Eng. 37(2-3) (2006) 200-212.

[6] Won J.P., Park C.G., J. Compos. Mater. 40(12) (2006) 1063-1076.

[7] Hammami A., Al-Ghuiliani N., Polym. Compos. 25(6) (2004) 609-616.

[8] Rahman A.H., Kingsley C., Richard J., Crimi J., Tuscan. 2 (1998) 501-511.

[9] Chen Y., Davalos J.F., Ray I., Kim H.Y., Struct. 78(1) (2007) 101-111.

[10] Gillham J.K., Polymer Int. 44(3) (1997) 262-276.

[11] Marouani S., CurtiL L., Hamelin P., Mater Structures 41(5) (2008) 831-851.

[12] Räsänen V., Penttala V., Cem Concr Res. 34(5) (2004) 813-820.

[13] Edwards K.L., Mater Des.19(1-2) (1998) 1-10.

[14] Bahadur S., Zheng Y., Wear. 137(2) (1990) 251-266.

[15] Pihtili H., Tosun N., Wear. 252 (2002) 979-84.

[16] Pihtili H., Tosun N., Compos Sci. Technol. 62 (2002) 367-370.

[17] Bhawani S.T., Michael J.F., J Wear. 162-164 (1993) 385-396.

[18] Myshkin N.K., Petrokovets M.I., Kovalv A.V., J Tribol Int. 38 (2005) 910-921. 
[19] Sampathkumaran P., Kishore S.S., Murali A., J Reinforce Plast Compos. 18(1) (1999) 55-62.

[20] Sampathkumaran P., Kishore S.S., Vynatheya S., Murali A., Kumar R.K., Wear. 237 (2000) 20-27.

[21] Collyer A.A., Rubber toughened engineering materials, London: Chapman and Hall; 1994.

[22] El-Tayep N.S., Gadelrap R.M., Wear. 192 (1996) 112-117,1996.

[23] Chand N., Naik A., Neogi S., Wear. 242 (2000) 38-46.

[24] Piggot M.R., Load-bearing fibre composite. Oxford: Pergamon Press; 1980.

[25] Kukureka S.N., Hooke C.J., Rao M., Liao P., Chen Y.K., Tribol Int. 32 (1999) 107-116.

[26] Srivastava V.K., Pathak J.P., Wear. 197 (1996) 145-150.

[27] ASM Handbook, ASM International. Materials Park, USA; 18, 1992.

[28] Ramesh R., Sampathkumaran P., Kishore Rao, RMVGK., Wear. 89 (1983) 131-139.

[29] Myshkin N.K, Petrokovets M.I, Kovalv A.V., J Tribol Int 38 (2005) 910-21.

[30] Sampathkumaran P Kishore, Seetharamu S, Murali A, Kumar RK. J Reinforce Plast Compos 1999;18(1):55-62.

[31] Sampathkumaran P. Kishore, Seetharamu S., Vynatheya S., Murali A., Kumar R.K., Wear. 237 (2000) 20-27.

[32] Collyer A.A., Rubber toughened engineering materials. London: Chapman and Hall; 1994.

[33] El-Tayep N.S., Gadelrap R.M., Wear 192 (1996) 112-117.

[34] Chand N., Naik A., Neogi S., Wear 242 (2000) 38-46.

[35] Piggot M.R., Load-bearing fibre composite. Oxford: Pergamon Press; 1980.

[36] Kukureka S.N., Hooke C.J., Rao M., Liao P., Chen Y.K., Tribol Int 32 (1999) 107-116.

[37] Srivastava V.K., Pathak J.P., Wear 197 (1995) 145-150.

[38] ASM Handbook, ASM International. Materials Park, USA; 1992. p. 18.

[39] Ramesh R., Sampathkumaran P. Kishore, Rao RMVGK., Wear. 89 (1983) 131. 